\title{
INTELLIGENT CAD/CAM SYSTEM FOR PROGRAMMING OF CNC MACHINE TOOLS
}

\author{
Klancnik, S.; Brezocnik, M. \& Balic, J. \\ University of Maribor, Faculty of Mechanical Engineering, Smetanova 17, 2000 Maribor, Slovenia \\ E-Mail:simon.klancnik@um.si,miran.brezocnik@um.si,joze.balic@um.si
}

\begin{abstract}
This paper suggests the automated programming of CNC-machine tools with the help of artificial intelligence. Based on a CAD-model of the product, the system, without any help from an expert, automatically prepares a CNC program, so that the machining is safe, accurate and time-efficient. The developed CAD/CAM system uses NSGA-II multi-objective optimisation and swarm intelligence. The system consists of a prediction and evaluation module. In a prediction module artificial intelligence suggests solutions that include information about tool path, selected tools and suggested cutting parameters. The evaluation module estimates the suggested solutions by considering the geometrical, technological and time criteria, and the criterion of efficiency of machining. A simulation model was developed for searching optimal solutions. In this paper, the developed system is experimentally tested using a test case of manufacturing. The test results confirmed that with the help of this method of artificial intelligence, machine tools can be automatically programmed.

(Received in May 2015, accepted in October 2015. This paper was with the authors 2 months for 1 revision.)
\end{abstract}

Key Words: NSGA-II, Multi-Objective Optimisation, Machine Tool, CNC Programming, $\mathrm{CAD} / \mathrm{CAM}$

\section{INTRODUCTION}

The properties of modern manufacturing systems are high automation, flexibility and autonomy. In spite of many efforts the preparation of the machining process remains a bottleneck during automated manufacturing processes. An experienced expert is still always needed for the programming of CNC machine tools to contribute his/her know-how and experience to improve the machining quality.

Today, two methods are used for preparing CNC machining programs, i.e., the seldom used manual preparation of $\mathrm{CNC}$ machining program and the use of CAM program packages [1]. Programming of machine tools is a complex process consisting of several problems that are mutually dependent and related. Research into the automatic programming of machine tools has been very topical in the past but researchers focused mainly on solving individual problems within a set of problems which only together represent the complex multi-criterion problem of automatic programming of CNC machine tools. Significant research has been executed into automatic tool selection in manufacturing [2-6]. Furthermore, researchers were busy trying to find the optimum tool paths [7-14]. The relevant cutting parameters must be selected in order to prepare a CNC program, allowing optimum machining according to given machining requirements. To that end, in the past research dealing with the optimisation of cutting parameters $[15,16]$ with respect to machining duration [17], machining costs [18], maximum extent of removed material [19], tool resistance to wear [20-23] and machined surface roughness [24-28] has been carried out.

This article proposes a new and effective model for the automatic programming of CNC machine tools. An important novelty of the proposed method is that the solving of complex problems is treated as a whole, i.e. it is not limited to one criterion only by idealising the other dependent criteria. This method of multi-criterion optimisation based on the evolutionary approach could be introduced into the process of automatic programming of machine tools. With the use of a computer-aided design environment and API interface our own simulation 
model has been developed. Artificial intelligence could be independently managed using the developed simulation model and the using of it for evaluating proposed machining solutions. The effectiveness of functioning regarding the proposed system was tested by a test work piece.

The article is composed as follows: Section 2 presents the proposed model of an intelligent CAD/CAM system and detailed descriptions of individual components of the prediction and evaluation module. The results from testing of the system by a selected test example of machining and discussion are presented in Section 3. The article ends with a short conclusion.

\section{METHODOLOGY AND SYSTEM COMPONENTS}

The proposed model of an intelligent CAD/CAM system would be generally useful for the programming of various CNC machine tools. Implementation of algorithms for testing the proposed model was limited to milling, which represented a 3D machining problem. The proposed CAD/CAM model consists of two modules, i. e. prediction and evaluation modules (see Fig. 1). On starting-up the user loads into the system a CAD model of the product prepared in one of the commercial packages for computer-aided design in order to manufacture the product on the machine tool. In the course of evolving the system develops the solutions and in the last step the best solution in the post-processing module is transformed into a form suiting the machine tool controls. Such a recorded form is called G code and the entire machining program is called the CNC machining program [29, 30].

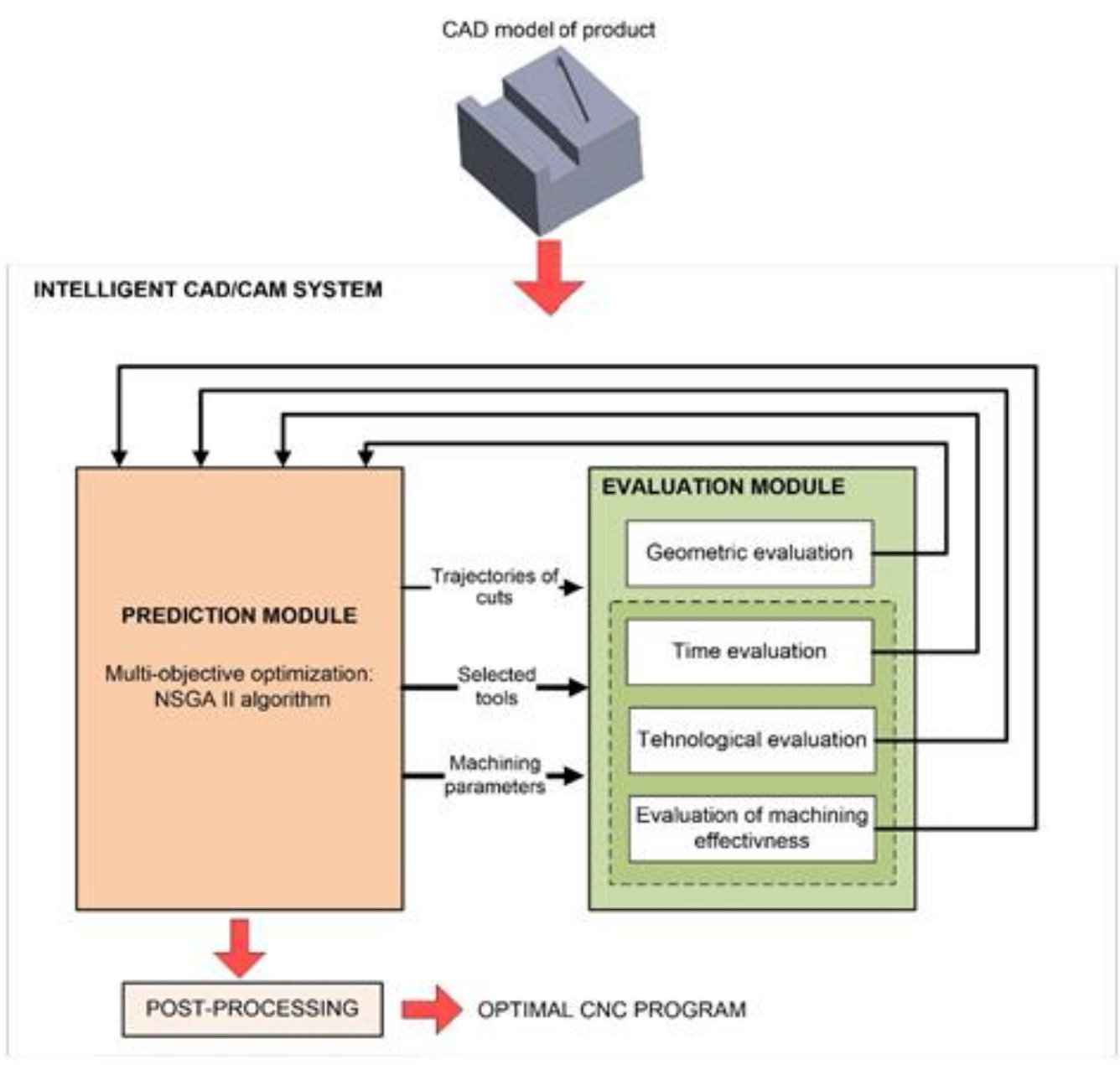

Figure 1: Model of an intelligent CAD/CAM system. 


\subsection{Prediction module}

In the prediction module the optimum CNC machining program is searched for by means of the evolutionary NSGA-II algorithm. The NSGA-II algorithm is a frequently used method of multi-objective optimisation and is described in detail in [31]. Machining on the machine tool is performed with $n$ cuts so that a certain volume of material is removed from the workpiece by each cut; the result is the desired product. The solution in the space of variables, thus, consists of $n$ cuts, each cut being carried out from starting point $Z$ to end point $K$ and travelling through the intermediate point $V$ (see Fig. 2). The proposed tool path between the point $Z$ and $K$ may be linear (see Fig. 2 a) or the tool travels on a circular arc with any radius (see Fig. 2 b).

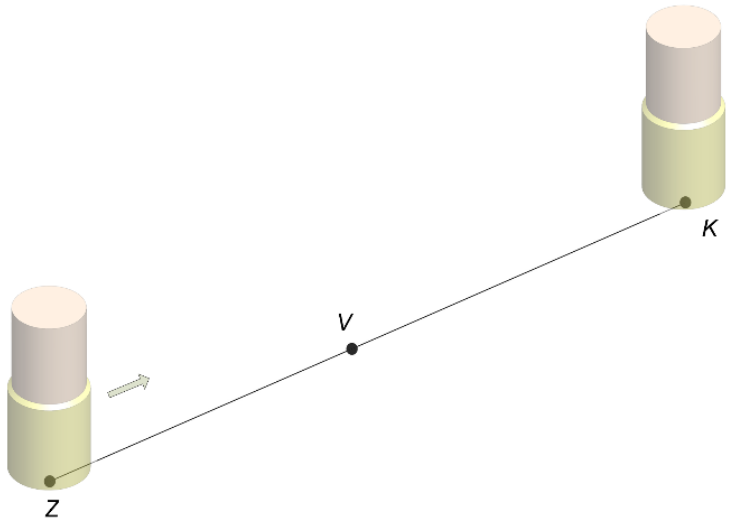

a) Linear tool path

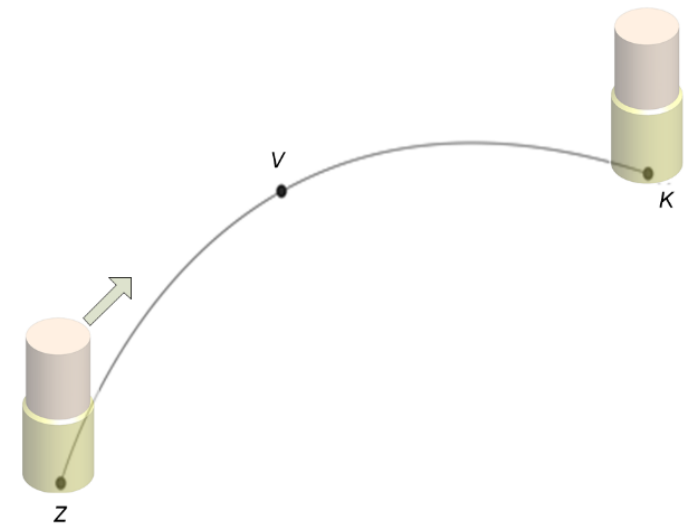

b) Circular tool path

Figure 2: Presentation of tool path.

Moreover, for execution of each cut the system proposes a tool with which the cut will be performed. Any number of tools that are available for machining and which the production model could use for preparing a CNC program can be added into the tool base.

Table I: Presentation of CUT $i$, which is one of the $n$ cuts in the population.

\begin{tabular}{|c|c|}
\hline \multicolumn{2}{|l|}{ CUT $i$} \\
\hline Description & Mark \\
\hline \multirow{3}{*}{ Starting point of cut $i$} & $X_{i, z}$ \\
\hline & $Y_{i, z}$ \\
\hline & $Z_{i, z}$ \\
\hline \multirow{3}{*}{ Intermediate point of cut $i$} & $X_{i, v}$ \\
\hline & $Y_{i, v}$ \\
\hline & $Z_{i, v}$ \\
\hline \multirow{3}{*}{ End point of cut $i$} & $X_{i, k}$ \\
\hline & $Y_{i, k}$ \\
\hline & $Z_{i, k}$ \\
\hline Tool for cut $i$ & $O_{i}$ \\
\hline Spindle speed of cut $i$ & $n_{s, i}$ \\
\hline Feed rate for cut $i$ & $f_{i}$ \\
\hline
\end{tabular}

For each tool the coded value, with which the tool is represented in the candidate solution, is determined. The system also determines the feed rate $f$ and the spindle speed $n_{s}$ for each 
cut. The values of the feed rate and spindle speed which may be proposed by the prediction module are limited by the tool maker's recommendations. When we focus on automatic programming of the milling machine, each cut in the candidate solution is represented by twelve variables or searching parameters as diagrammatically shown in Table I.

\subsection{Evaluation module}

Any solution prepared by the prediction module is evaluated in the evaluation module. Based on that evaluation, the prediction module develops a new generation of solutions. That process is repeated until the optimum or near optimum CNC machining program has been proposed. The evaluation module evaluates each solution on the basis of four criteria and the fitness function is written as follows:

where:

$$
f(\boldsymbol{x})=\left(f_{\mathrm{g}}(\mathbf{x}), f_{\mathrm{t}}(\mathbf{x}), f_{\mathrm{ti}}(\mathbf{x}), f_{\mathrm{a}}(\mathbf{x})\right)
$$

$f_{\mathrm{g}}(\mathbf{x})$ : geometry criterion,

$f_{\mathrm{t}}(\mathbf{x})$ : technological criterion,

$f_{\mathrm{ti}}(\mathbf{x})$ : time criterion,

$f_{\mathrm{a}}(\mathbf{x})$ : machining efficiency criterion.

\section{Geometric Evaluation}

Geometric evaluation means the evaluation of the proposed solution with respect to the physical limitations during the execution of machining. If the system should propose a safe CNC machining program, potential collisions between tool, workpiece and machine tool must be verified for each proposed cut. If the solution contains one or more collisions, punishment of such subject is effected by allotting a bad total mark $f(\mathbf{x})$ to that subject irrespective of the fact of what the mark for that subject according to other criteria is. Such a subject is promptly isolated by evolution.

\section{Technological Evaluation}

In addition to cut trajectories the prediction module also proposes the spindle speed $n_{\mathrm{s}}$ the feed rate $f$ for each cut and the tool for execution of that cut. Furthermore, the information about the depth of cut $a_{d}$ is extracted by means of the developed machining simulation. All those data are inputs into the developed module for the technological evaluation, where, by the use of the swarm intelligence method, the surface roughness machined with the proposed cut $i$ is predicted. With the use of the particle swarm optimisation algorithm the optimum values of coefficients $k_{1}$ up to polynomial $k_{10}$ represented in Eq. (2) are searched for.

$$
R a=k_{1}+k_{2} \cdot f+k_{3} \cdot n_{s}+k_{4} \cdot a+k_{5} \cdot f \cdot n_{s}+k_{6} \cdot f \cdot a+k_{7} \cdot n_{s} \cdot a+k_{8} \cdot f^{2}+k_{9} \cdot n_{s}^{2}+k_{10} \cdot a^{2}
$$

Each particle in the swarm is evaluated with the following evaluation function [25]:

$$
\Delta=\frac{\sum_{i=1}^{n} \Delta_{i}}{n}
$$

where $n$ is the number of experimental measurements in the training base and $\Delta_{i}$ is the error of an individual sample as a percentage, which is written as follows:

$$
\Delta_{i}=\frac{\left|E_{i}-P_{i}\right|}{E_{i}} \times 100 \%
$$

In Eq. (4) $E_{i}$ represents the measured surface roughness and $P_{i}$ the predicted roughness.

\section{Time Evaluation}

The CNC machining program must be so composed that such tools from the tool database and such cut trajectories will be used that the machining time will be as short as possible to that end, the fitness function of the time evaluation of the subject is developed as follows. 


$$
f_{t i}=\sum_{i=1}^{n} \frac{l_{d, i}}{f_{i}}+\sum_{i=1}^{n-1} \frac{l_{j, i}}{v_{j}}+\frac{l_{z}}{v_{j}}+\frac{l_{k}}{v_{j}}+m \cdot t_{m}
$$

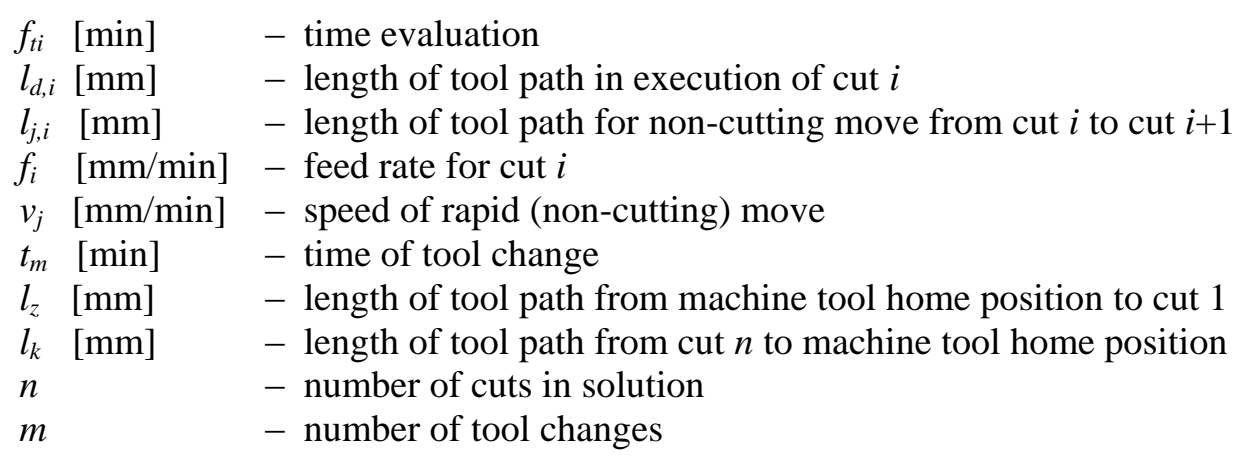

In Eq. (5) the time necessary to execute all working and idle motions and the time used for tool change are considered.

\section{Accuracy Evaluation}

The system must propose such a CNC machining program that only the material necessary to obtain the desired product from the work piece will be removed from the workpiece. In connection with machining efficiency two types of irregularities may occur when machining on the machine tool, i. e. the tool may remove too much or too little material from the workpiece. Accordingly, the following function of machining efficiency evaluation was developed:

$$
f_{o}=w_{1} \cdot V_{u}+w_{2} \cdot V_{w}
$$

In Eq. (6) $V_{u}$ means the volume of material which could have been removed during machining but was not removed by the proposed solution (non-machined volume).

CAD model of product

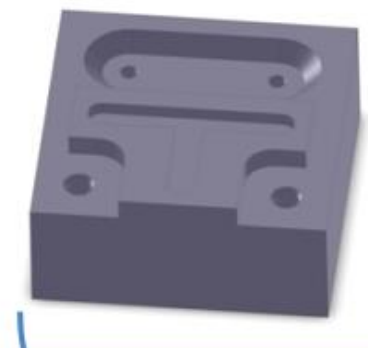

Comparison of product $\mathrm{CAD}$ model with simulation result

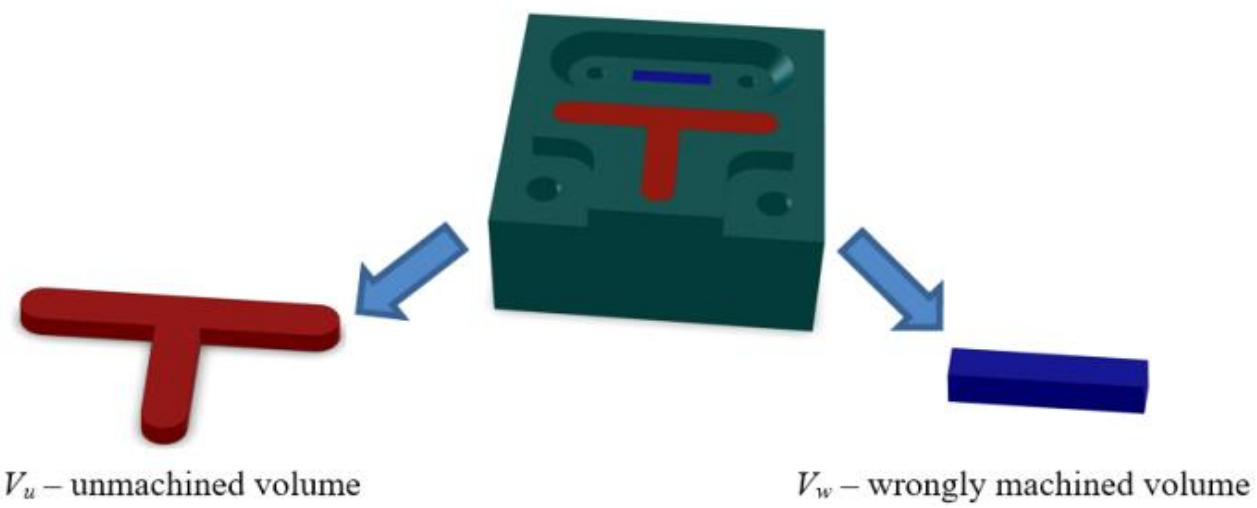

Figure 3: Example of CAD model of product comparison with machining simulation result. 
The volume of material which the proposed solution removes from the workpiece, though it ought not to remove it (wrongly machined volume) is designated $V_{w}$ in Eq. (6). Weights $w_{1}$ and $w_{2}$ help to determine to what extent the individual volume should be considered in the evaluation of machining efficiency. It should always apply that the sum of values of weights $w_{1}$ and $w_{2}$ is equal to 1 . The volume too little or too much removed is so determined that the system compares the CAD model of the product that is to be manufactured, to the result of the machining simulation. An example of machining efficiency evaluation is diagrammatically shown in Fig. 3.

\section{RESULTS AND DISCUSSION}

Functioning of the proposed CAD/CAM model was tested by implementing the system in the .NET environment in program language $\mathrm{C \#}$ and with the use of applying programming interface (API) and computer-aided design environment SolidWorks. Here below, the test results from the functioning of the developed system with selected a test example of machining will be presented. Moreover, the results of functioning of the developed module for technological evaluation of cuts proposed by the prediction model will also be presented.

\subsection{Technological evaluation}

Training and testing of the technological evaluation module were performed on the basis of experimental measurements carried out by Lou [32] within the framework of research. The experiment was executed with the use of a vertical CNC milling machine, namely for workpiece from aluminium 6061. The cube-shaped workpiece with side $L=25.4 \mathrm{~mm}$ and the tool of $D=19.05 \mathrm{~mm}$ diameter were used. Measurements of surface roughness $R_{a}$ were performed for cuts with different feeding and rotating speeds and different cut depths. In total 156 measurements were performed. 120 samples $(77 \%)$, representing our training base, were used for training of the system. For testing, 36 measurements $(23 \%)$, representing the test base, were used. In the course of the experiment, the following control parameters of the PSO algorithm were selected for best convergence:

- Number of particles in swarm: 35

- Number of iterations: 7500

- Particle size: 10

- Acceleration coefficient $c_{1}: 1.2$

- Acceleration coefficient $c_{2}: 2.4$

Through evolution, the developed system searched for optimum or near optimum values of the polynomial model's coefficients marked $k_{1}$ to $k_{10}$ in Eq. (2). The best solution, proposed for the algorithm for calculating the surface roughness, was as follows:

$$
\begin{gathered}
R_{a}=112,05-0,11 \cdot n_{s}+1,54 \cdot f-1,65 \cdot a_{d}-3,78 \cdot 10^{-4} \cdot n_{s} \cdot f+6,4 \cdot 10^{-4} \cdot n_{s} \cdot a_{d}-\cdots \\
\ldots-1,7 \cdot 10^{-3} \cdot f \cdot a_{d}+2,52 \cdot 10^{-5} \cdot n_{s}^{2}-6,95 \cdot 10^{-4} \cdot f^{2}+7,8 \cdot 10^{-3} \cdot a_{d}^{2}
\end{gathered}
$$

With the use of Eq. (7) the surface roughness reached when executing the cut with the proposed machining parameters: $f$ - feed rate, $n_{s}$ - spindle speed and $a_{d}$ - cut depth, can be predicted. The average error of the predicted values with respect to performed roughness measurements amounted to $\Delta_{t r}=9.07 \%$ for the samples from the training base. For the samples from the training base (120 samples) Fig. 4 graphically shows the deviation of predicted values from the measured roughness of the machined surface.

The system was tested using the test base. In that case, the average error of predicted values with respect to known experimental measurements of roughness was equal to $\Delta_{t s}=10.09 \%$. For the samples from the test base (36 measurements) Fig. 5 graphically shows the percentage deviation of predicted surface roughness from the measured roughness. 


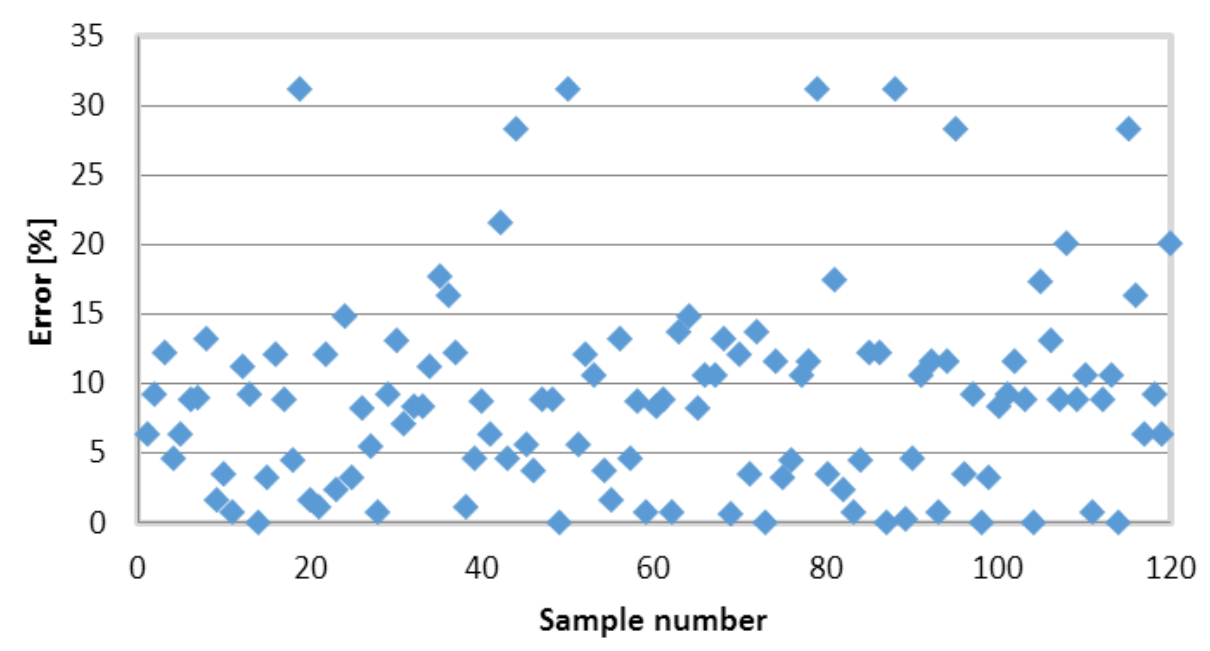

Figure 4: Prediction error for samples from the learning database.

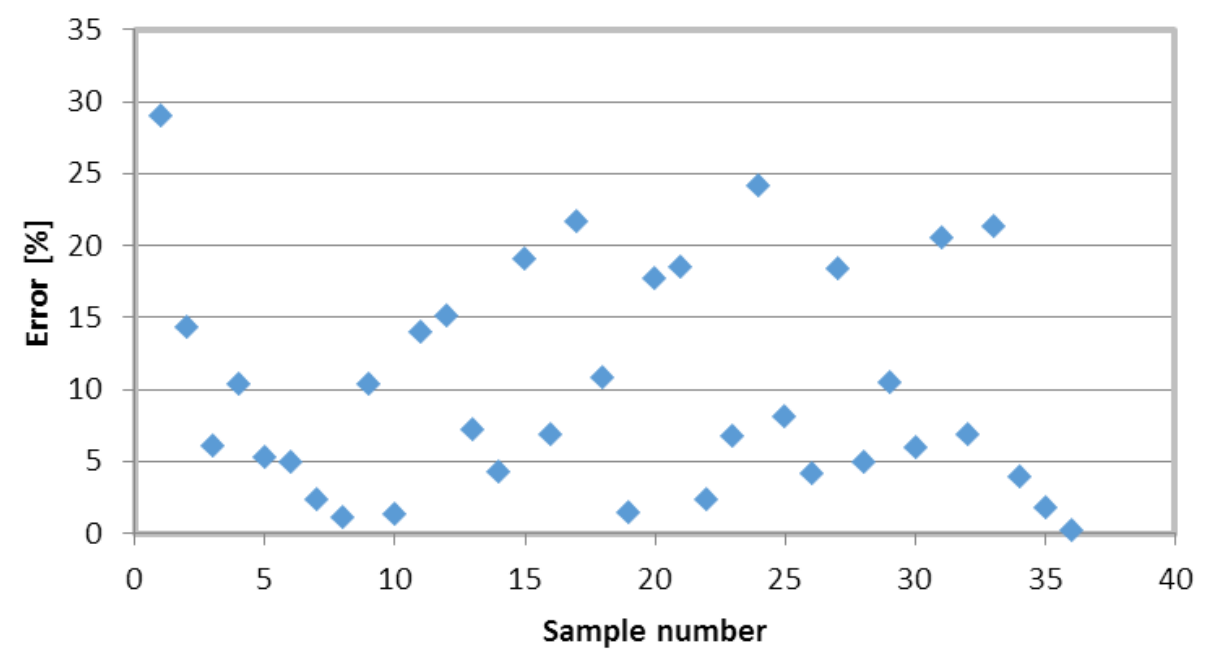

Figure 5: Prediction error for samples from the testing database.

\subsection{Test case of machining}

The proposed model was tested with different test examples of machining. Here below, functioning of the system when searching for the solution for machining the test product on a three-axis milling machine is presented. The system searched for the solution optimal with respect to time $f_{t i}$ and machining efficiency $f_{a}$. When searching for the solution, in addition to those two criteria, it also considered the geometric criterion $f_{g}$ guaranteeing safety of the proposed machining. In the selected test example the criterion of machining technology was not considered, therefore, artificial intelligence did not affect prediction of the optimum spindle speed and feed rate. For all cuts, constant spindle speed $n_{s}=650 \mathrm{~min}^{-1}$ and feed rate speed $f=120 \mathrm{~mm} / \mathrm{min}$ were selected. Fig. 6 shows the CAD model of the test product supposed to be made by the three-axis milling machine. It must be pointed out that the developed intelligent CAD/CAM system had previously not seen such a product; moreover, searching for the solution took place completely automatically without any input of manufacturing know-how or additional assistance of the expert.

The database of available tools consisted of four different milling cutters is shown in Fig. 7. Out of all milling cutters the system used only those better for making the test product from Fig. 6. 


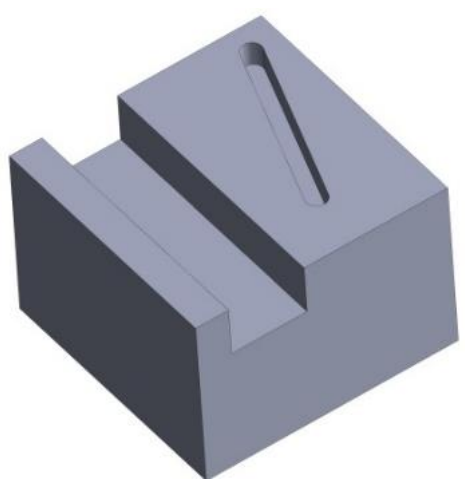

Figure 6: CAD model of test product.

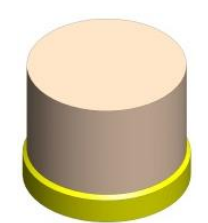

$\mathrm{T} 1$ - face mill Ø63

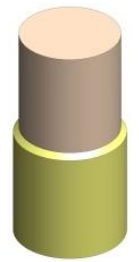

$\mathrm{T} 3$ - end mill Ø20

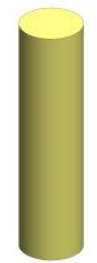

$\mathrm{T} 2$ - end mill Ø8

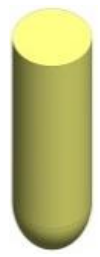

T4 - ball nose cutter Ø6

Figure 7: Available tools for manufacture of test product.

When using the NSGA-II algorithm, the system does not propose only one optimum solution, but a set of solutions in which each solution is best according to certain criteria. Out of all the proposed solutions the user may select randomly the solution that is best suited for the manufacture of that product. When solving the test example, the population consisted of 80 subjects. The evaluation and prediction module was limited to linear cuts to reach fastest possible convergence. In the first generation, the proposed solutions were random in nature, whereas in the course of evolution their quality improved. Fig. 8 shows some bad machining solutions from the initial generations of evolution.
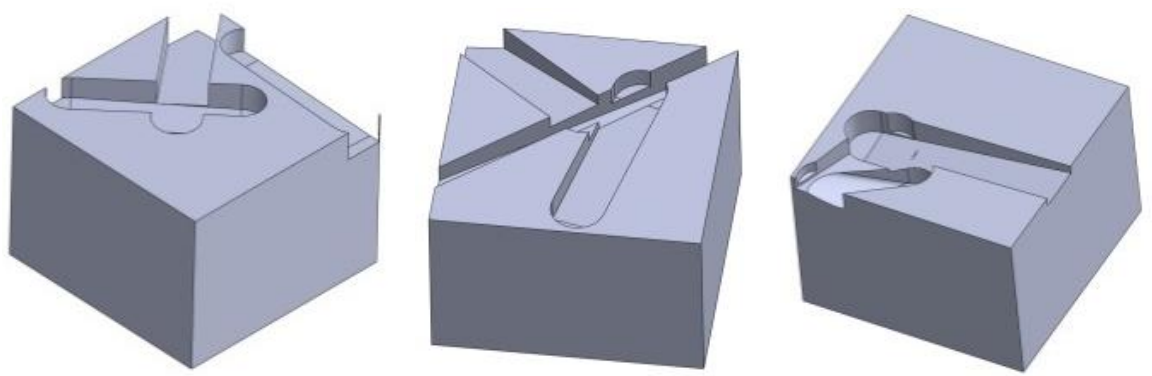

Slika 8: Examples of proposed manufacturing for test case in initial generations.

After 115 generations, the search solution was stopped. The result was a set of optimum solutions (Pareto optimal front) graphically shown in Fig. 9. In that graph, the abscissa axis represents the time necessary for the manufacture of the test product on the three-axis milling 
machine and the ordinate axis represents the evaluation of machining efficiency with the proposed CNC program. The machining efficiency $f_{a}$ was determined by the use of Eq. (6) in which the weight $w_{1}=0.3$ and the weight $w_{2}=0.7$.

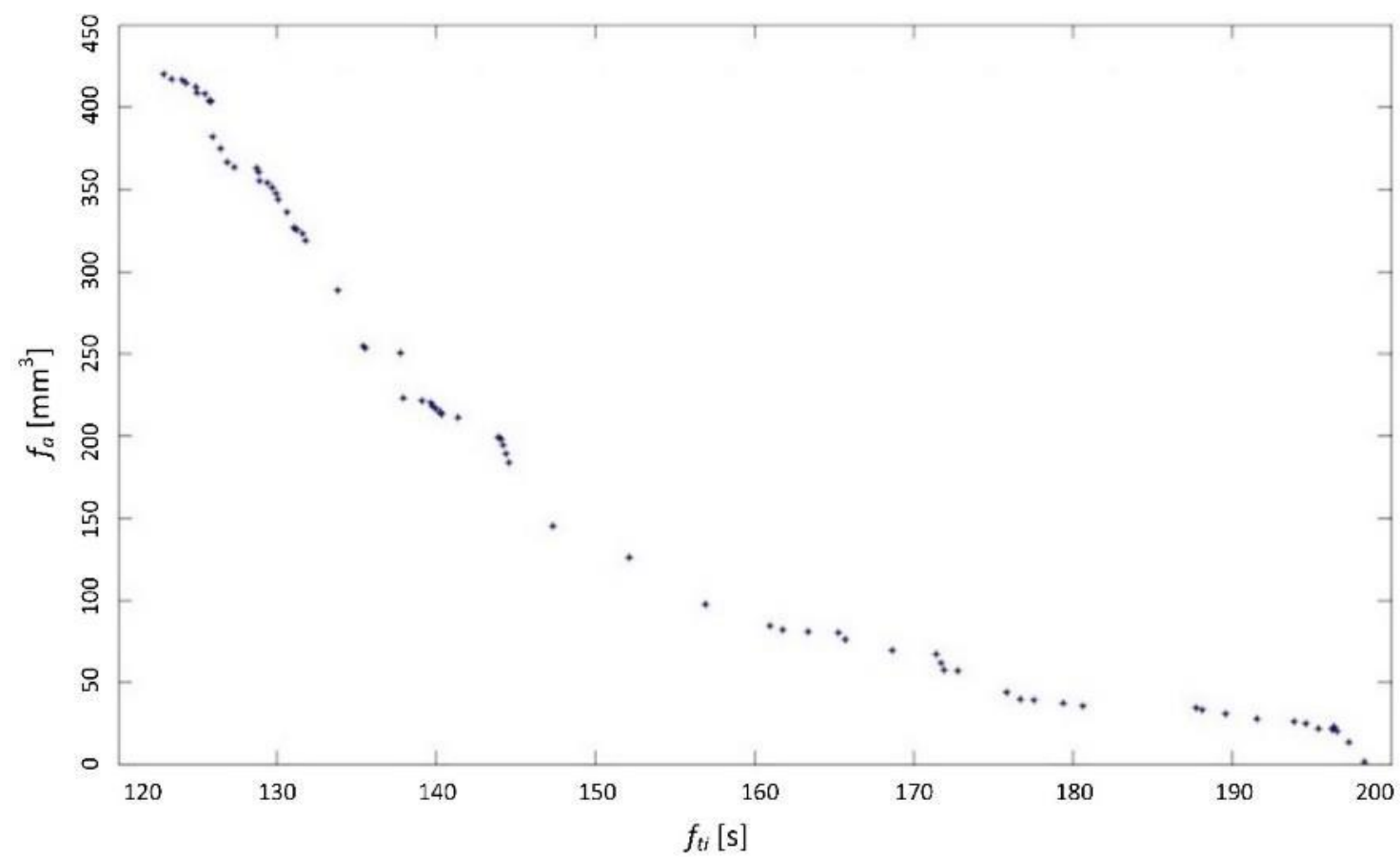

Figure 9: Graphical representation of optimum solutions (Pareto optimal front).

It must be emphasised that all solutions from Fig. 9 were also safe, i.e., without collisions. It is unreasonable to determine what solution is of higher quality, whether the one with less or the one with more collisions, as the only good and practically usable solution is completely without collisions. Therefore the geometric criterion was considered to be a limitation, implying that in each generation the solutions with one or more collisions were isolated. Potential collisions were established by means of the developed system for simulation of the proposed machining.

Fig. 9 shows that the fastest proposed machining takes a little more than 2 minutes but in such machining all the necessary material is not removed from the workpiece and that some wrong material is removed. Fig. 9 also shows that the solutions are uniformly distributed on the Pareto optimal front, namely to the solution where machining takes as much as 3 minutes. Within that time, with constantly adjusted feed rate and spindle speed, a quite correct test product can be made on the machine tool, implying that there will not be too little or too much removed material when machining (machining efficiency $f_{a}$ is equal to 0 ). The process of the solution so proposed is diagrammatically shown in Fig. 10.

It can be seen that the system automatically proposed a solution in which all the necessary material is removed from the workpiece, so that subsequent machining is unnecessary. On the other hand, too much material is not removed from the workpiece in the proposed solution; consequently, machining is quite correct. Because of simplicity of the test example it can be claimed that the proposed tool path is optimal or at least near optimal. The tool travels so that the cut $i+1$ starts always as close as possible to the cut $i$ end. Therefore, the idle tool path between individual cuts is as short as possible or does not exist at all. Furthermore, the cuts for which the system proposed the use of identical tools are successively performed. In that way, the number of tool changes during machining is reduced resulting in shorter time of machining, as each tool change takes a certain time. The intelligence of the system is also obvious regarding the selections of tools for executing individual cuts, as throughout 
evolution, the system has learnt to reduce the machining path and, as a result, the time of machining, if a tool of greater diameter is used.

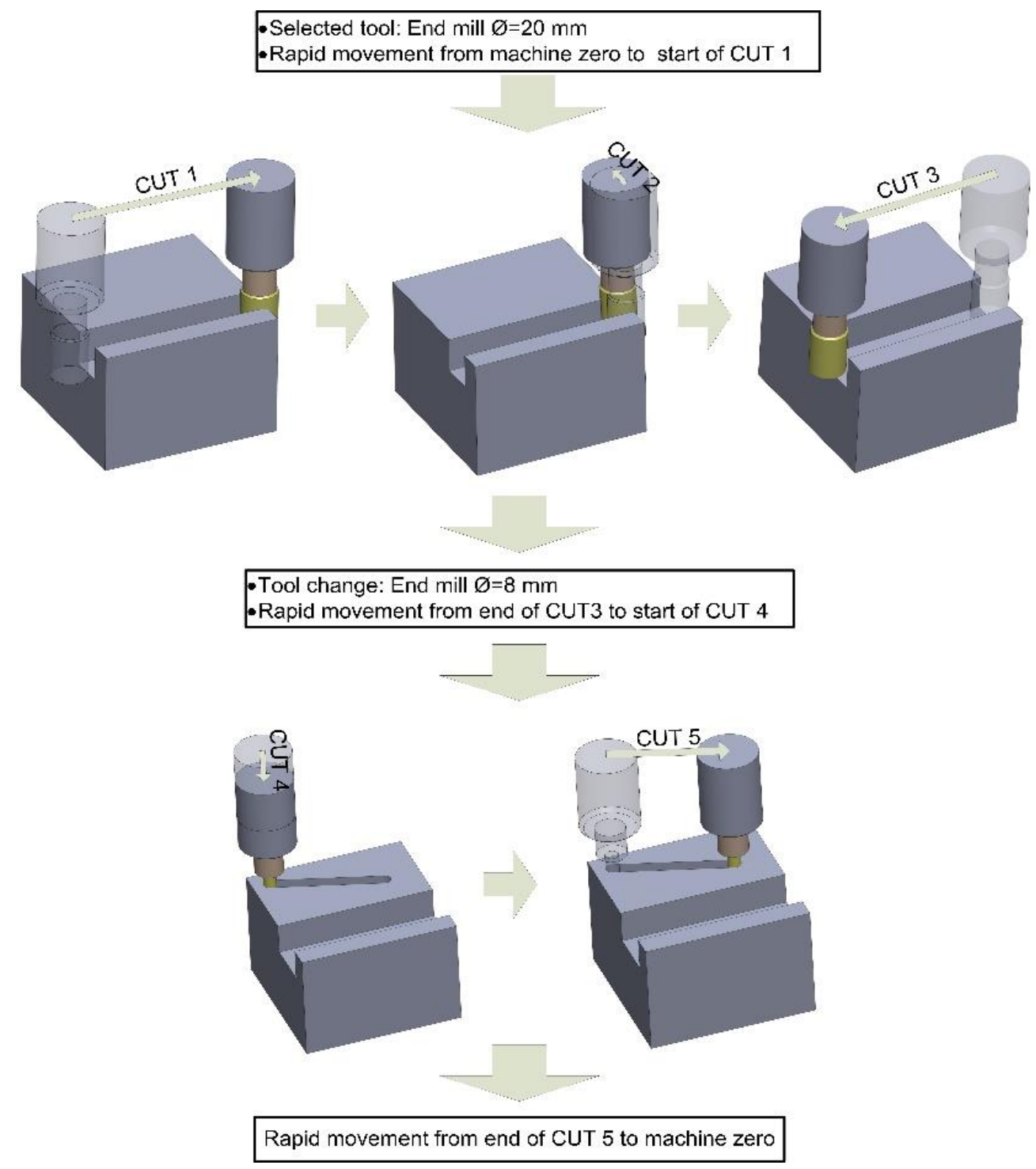

Figure 10: Schematic representation of machining using the proposed CNC program.

\section{CONCLUSION}

This article presents a new approach to automatic programming of the $\mathrm{CNC}$ machine by the use of artificial intelligence. The proposed CAD/CAM model is suitable for solving 3D as well as 2D machining problems [33]; testing the functioning of the system was limited to automatic programming of a 3-axis CNC milling machine. The developed model approaches the solving of the complex problem of programming a machine tool as a whole by using the evolutionary multi-criterion optimisation algorithm NSGA-II. For evaluation of solutions proposed by the NSGA-II algorithm the use of API interface and computer-aided design environment helped us to develop our own machining simulator. As already stated in the article the results of testing of the developed system with the selected test example confirmed that functioning of the system is efficient and that the system is capable automatically, without the expert's assistance to prepare a correct and efficient CNC machining program for a relatively simple prismatic product. The results of research represent a contribution in the sphere of intelligent machine tools and systems. 
As an extension to this study, we suggest research directions for the future work. Any solution proposed by the prediction module must be evaluated with the developed machining simulator posing a bottle-neck with respect to time exactness of the system's operation. It would be reasonable to improve the evolution process of the proposed solution in order to reduce the time exactness of the algorithm; so the system would also become suitable for solving complex products with free surfaces. In the future, it would also be reasonable to test the system's operation with other multi-criterion optimisation methods, such as the multiobjective particle swarm optimiser [34].

\section{REFERENCES}

[1] Sajko, N.; Kovacic, S.; Balic, J. (2013). Simulation based CAD/CAM model for extrusion tools, Advances in Production Engineering \& Management, Vol. 8, No. 1, 33-40, doi:10.14743/ apem2013.1.151

[2] Balic, J.; Cus, F.; Vaupotic, B. (2011). Intelligent automatic cutting-tool selections for turning operations, International Conference on Artificial Intelligence and Machine Learning, Dubai, United Arab Emirates, 7 pages

[3] Chen, Y.-H.; Lee, Y.-S.; Fang, S.-C. (1998). Optimal cutter selection and machining plane determination for process planning and NC machining of complex surfaces, Journal of Manufacturing Systems, Vol. 17, No. 5, 371-388, doi:10.1016/S0278-6125(98)80004-6

[4] Ding, X. M.; Lu, Y. Q.; Liu, P. L. (2005). Optimal cutter selection for complex mould machining, SIM Tech Technical Reports, Vol. 6, No. 1, 84-88

[5] Yao, Z.; Gupta, S. K.; Nau, D. S. (2001). A geometric algorithm for finding the largest milling cutter, Journal of Manufacturing Processes, Vol. 3, No. 1, 1-16, doi:10.1016/S1526$\underline{6125(01) 70029-1}$

[6] Mwinuka, T. E.; Mgwatu, M. I. (2015). Tool selection for rough and finish CNC milling operations based on tool-path generation and machining optimisation, Advances in Production Engineering \& Management, Vol. 10, No. 1, 18-26, doi:10.14743/apem2015.1.189

[7] Klancnik, S.; Balic, J.; Cus. F.; Veza, I. (2009). Intelligent model for machining strategy prediction, International Scientific Conference on Production Engineering - CIM 2009, Biograd, 115-118

[8] Klancnik, S.; Balic, J., Cus, F. (2010). Intelligent prediction of milling strategy using neural networks, Control and Cybernetics, Vol. 39, No. 1, 9-24

[9] Lartigue, C.; Thiebaut, F.; Maekawa, T. (2001). CNC tool path in terms of B-spline curves, Computer-Aided Design, Vol. 33, No. 4, 307-319, doi:10.1016/S0010-4485(00)00090-7

[10] Park, S. C.; Chang, M. (2010). Tool path generation for a surface model with defects, Computers in Industry, Vol. 61, No. 1, 75-82, doi:10.1016/j.compind.2009.07.003

[11] Vosniakos, G.; Papapanagiotou, P. (2000). Multiple tool path planning for NC machining of convex pockets without islands, Robotics and Computer-Integrated Manufacturing, Vol. 16, No. 6, 425-435, doi:10.1016/S0736-5845(00)00025-9

[12] Brezocnik, M.; Kovacic, M.; Ficko, M.; Balic, J. (2005). Programming CNC lathes by genetic algorithms, Proceedings of the $15^{\text {th }}$ International Conference on Flexible Automation and Intelligent Manufacturing, Vol. 1, 163-170

[13] Balic, J.; Klancnik, S.; Brezovnik, S. (2008). Feature extraction from CAD model for milling strategy prediction, Strojniski vestnik - Journal of Mechanical Engineering, Vol. 54, No. 5, 301307

[14] Gjelaj, A.; Balic, J.; Ficko, M. (2013). Intelligent optimal tool selections for CNC programming of machine tools, Transactions of FAMENA, Vol. 37, No. 3, 31-40

[15] Hrelja, M.; Klancnik, S.; Irgolic, T.; Paulic, M.; Jurkovic, Z.; Balic, J.; Brezocnik, M. (2014). Particle swarm optimization approach for modelling a turning process, Advances in Production Engineering \& Management, Vol. 9, No. 1, 21-30, doi:10.14743/apem2014.1.173

[16] Brajlih, T.; Valentan, B.; Balic, J.; Drstvensek, I. (2011). Speed and accuracy evaluation of additive manufacturing machines, Rapid Prototyping Journal, Vol. 17, No. 1, 64-75, doi: $\underline{10.1108 / 13552541111098644}$ 
[17] Chua, M. S.; Rahman, M.; Wong, Y. S.; Loh, H. T. (1993). Determination of optimal cutting conditions using design of experiments and optimization techniques, International Journal of Machine Tools \& Manufacture, Vol. 33, No. 2, 297-305, doi:10.1016/0890-6955(93)90081-5

[18] Wang, J. (1993). Multiple-objective optimisation of machining operations based on neural network, International Journal of Advanced Manufacturing Technology, Vol. 8, No. 4, 235-243, doi:10.1007/BF01748633

[19] Cus, F.; Sokovic, M.; Kopac, J.; Balic, J. (1997). Model of complex optimization of cutting conditions, Journal of Materials Processing Technology, Vol. 64, No. 1-3, 41-52, doi:10.1016/ $\underline{\text { S0924-0136(96)02552-6 }}$

[20] Krain, H. R.; Sharman, A. R. C.; Ridgway, K. (2007). Optimisation of tool life and productivity when end milling Inconel 718TM, Journal of Materials Processing Technology, Vol. 189, No. 13, 153-161, doi:10.1016/j.jmatprotec.2007.01.017

[21] Tamang, S. K.; Chandrasekaran, M. (2015). Modeling and optimization of parameters for minimizing surface roughness and tool wear in turning $\mathrm{Al} / \mathrm{SiCp} \mathrm{MMC}$, using conventional and soft computing techniques, Advances in Production Engineering \& Management, Vol. 10. No. 2, 59-72, doi:10.14743/apem2015.2.192

[22] Hrelja, M.; Klancnik, S.; Balic, J.; Brezocnik, M. (2014). Modelling of a turning process using the gravitational search algorithm, International Journal of Simulation Modelling, Vol. 13, No. 1, 30-41, doi:10.2507/IJSIMM13(1)3.248

[23] Cerce, L., Pusavec, F.; Kopac., J. (2015). A new approach in spatial tool wear analysis and monitoring, Strojniski vestnik - Journal of Mechanical Engineering, Vol. 61, No. 9, 489-497, doi:10.5545/sv-jme.2015.2512

[24] Baek, D. K.; Ko, T. J.; Kim H. S. (2001). Optimization of feedrate in a face milling operation using a surface roughness model, International Journal of Machine Tools and Manufacture, Vol. 41, No. 3, 451-462, doi:10.1016/S0890-6955(00)00039-0

[25] Brezocnik, M.; Kovacic, M.; Ficko, M. (2004). Prediction of surface roughness with genetic programming, Journal of Materials Processing Technology, Vol. 157-158, 28-36, doi:10.1016/j.jmatprotec.2004.09.004

[26] Suresh, P. V. S.; Rao, P. V.; Deshmukh, S. G. (2002). A genetic algorithmic approach for optimization of surface roughness prediction model, International Journal of Machine Tools and Manufacture, Vol. 42, No. 6, 675-680, doi:10.1016/S0890-6955(02)00005-6

[27] Zuperl, U.; Cus, F. (2015). Simulation and visual control of chip size for constant surface roughness, International Journal of Simulation Modelling, Vol. 14, No. 3, 392-403, doi:10.2507/IJSIMM14(3)2.282

[28] Begic-Hajdarevic, D.; Cekic, A.; Mehmedovic, M.; Djelmic, A. (2015). Experimental study on surface roughness in abrasive water jet cutting, Procedia Engineering, Vol. 100, 394-399, doi:10.1016/j.proeng.2015.01.383

[29] Krzic, P.; Stoic, A.; Kopac, J. (2009). STEP-NC: A new programming code for the CNC machines, Strojniski vestnik - Journal of Mechanical Engineering, Vol. 55, No. 6, 406-417

[30] Staroveski, T.; Brezak, D.; Udiljak, T. (2013). LinuxCNC - the enhanced machine controller: application and an overview, Technical Gazette, Vol. 20, No. 6, 1103-1110

[31] Deb, K.; Pratap, A.; Agarwal, S.; Meyarivan, T. (2002). A fast elitist multiobjective genetic algorithm: NSGA-II, IEEE Transactions on Evolutionary Computation, Vol. 6, No. 2, 182-197, doi:10.1109/4235.996017

[32] Lou, S.-J. (1997). Development of four in-process surface recognition systems to predict surface rougness in end milling, Doctoral Thesis, Iowa State University, Ames, Iowa

[33] Kundrak, J.; Gyani, K.; Deszpoth, I.; Sztankovics, I. (2014). Some topics in process planning of rotational turning, Engineering Review, Vol. 34, No. 1, 23-32

[34] Hassine, H.; Barkallah, M.; Bellacicco, A.; Louati, J.; Riviere, A.; Haddar, M. (2015). Multi objective optimization for sustainable manufacturing, application in turning, International Journal of Simulation Modelling, Vol. 14, No. 1, 98-109, doi:10.2507/IJSIMM14(1)9.292 